\title{
BMJ Open Determinants of drug prices: a systematic review of comparison studies
}

\author{
Jules M Janssen Daalen (D) , 1,2,3 Anouk den Ambtman (D) ,,4 \\ Mark Van Houdenhoven, ${ }^{2,4}$ Bart J F van den Bemt ${ }^{3,5,6}$
}

To cite: Janssen Daalen JM, den Ambtman A, Van Houdenhoven $\mathrm{M}$, et al. Determinants of drug prices: a systematic review of comparison studies. BMJ Open 2021;0:e046917. doi:10.1136/ bmjopen-2020-046917

- Prepublication history and additional supplemental material for this paper are available online. To view these files, please visit the journal online (http://dx.doi.org/10.1136/ bmjopen-2020-046917).

Received 24 November 2020 Accepted 08 June 2021

Check for updates

(c) Author(s) (or their employer(s)) 2021. Re-use permitted under CC BY-NC. No commercial re-use. See rights and permissions. Published by BMJ.

${ }^{1}$ Faculty of Medical Sciences, Radboud University, Nijmegen, The Netherlands

${ }^{2}$ Staff Board of Directors, Sint Maartenskliniek, Nijmegen, The Netherlands

${ }^{3}$ Department of Pharmacy, Sint Maartenskliniek, Nijmegen, The Netherlands

${ }^{4}$ Institute for Management Research, Radboud University, Nijmegen, The Netherlands ${ }^{5}$ Department of Pharmacy, Radboud University Medical Center, Nijmegen, The Netherlands

${ }^{6}$ Department of Clinical Pharmacy and Toxicology, Maastricht University Medical Center +, Maastricht, Netherlands

\section{Correspondence to} Jules M Janssen Daalen; jules.m.janssendaalen@ radboudumc.nl

\begin{abstract}
Objective In this systematic review on drug price comparison studies, we report on recent determinants of drug prices in a national and international context to facilitate regulation of drug prices by purchasers and policymakers worldwide. Determinants of drug prices were divided into non-modifiable and modifiable and were categorised as pertaining to a country's income level, pharmaceutical market system and its policies and government.
\end{abstract}

Primary outcome Determinants of drug prices or price variance.

Design We systematically searched PubMed, EMBASE, Web of Science and Cochrane Library for peer-reviewed articles published between 2004 and 22 July 2020 that reported an association of the primary outcome with one or more determinants. We performed a best-evidence synthesis of these associations for determinants covered in at least three studies.

Results 31 publications were included. Only one publication described net drug prices and 30 described retail drug prices. Five modifiable determinants were associated with lower retail prices: generic market portion, discounts, tendering policies, central (governmental) purchasing and pricing regulation schemes. The originators market portion and a system in which markups are common were associated with higher retail prices. Retail prices were highest in the USA, even compared with other high-income countries. A positive association between national income level and drug retail prices could not be established among middle-income and high-income countries. Retail prices were highest in low-income countries when adjusted for purchasing power parity. Conclusions Literature on determinants of net drug prices is extremely sparse. Various healthcare system interventions, market-specific and governmental regulations are consistently associated with lower retail prices. Some interventions are easily implementable in developing or middle-income countries, such as tendering, central purchasing and fixed pricing regulation schemes. Net drug price comparison studies are needed to overcome the lack of price transparency and to quantify the effectiveness of policy measures on net drug prices.

\section{INTRODUCTION}

The global average share of healthcare costs in gross domestic product (GDP) increased from $4.6 \%$ of GDP in 1970 to $9.0 \%$ of GDP in $2016 .^{1}$ Several factors contributed to this
Strengths and limitations of this study

- A systematic review on drug price comparison studies in peer-reviewed literature was conducted to assess all recently identified modifiable and nonmodifiable determinants of drug prices.

- Only one published study conducted determinant analyses with net drug prices, while the rest included retail drug prices.

- The structured best-evidence synthesis is able to quantify heterogeneous evidence and summarises the association between drug price (variance) and the reported determinants.

- This study design only allows for correlative analysis and cannot establish direct causal associations between determinants and price (variance).

rise, such as ageing populations, technological advances, the development of (expensive) new drugs and increased insurance coverage. Consequently, countries worldwide face the challenge of decreasing this healthcare cost burden. A significant driver of rising healthcare costs is pharmaceutical expenditure, so interventions to decrease drug costs through lower drug prices are warranted. Pharmaceutical expenditure is expected to reach 1.5 trillion dollars in $2023 .{ }^{23}$ Currently, a lack of transparency due to contract and pricing agreements between purchasers and manufacturers of drugs limits insight into net drug prices because price comparisons are based on retail prices. Net drug prices are the prices actually paid by the purchasing healthcare institute, while retail prices exclude various individual pricing agreements such as rebates. ${ }^{4}$ The effects of various policy measures are, therefore, unavailable to most purchasers and policymakers, which makes the drug price market opaque and actual comparisons of prices impossible. ${ }^{5-8}$ The global drug price discussion is tremendous, but it remains unclear how drug prices are determined.

By comparing drug prices within and across different countries, determinants of drug prices can be identified. We make a 
distinction between determinants that are modifiable by policymakers and determinants that are not. Modifiable determinants could act as a target for potential interventions to decrease drug costs. Present drug policies are highly heterogeneous and have varying effects on drug prices. Therefore, identifying and harmonising effective price management strategies may aid in accomplishing lower prices. However, international and national price comparison studies of net drug prices are scarce in the literature, which forms a bottleneck to compare drug prices. To our knowledge, the first publication that quantified drug price differences was performed in 1971 in the USA. ${ }^{9}$ In this study, the net price paid by the US government was compared with the purchasing price of community pharmacies for the 50 most prescribed medications. Central governmental purchasing by the USA resulted in a relative discount of nearly $50 \%$ over local pharmacies. Since then, research on drug prices (excluding price ratios) and, more specifically, net drug prices has been very limited, but in recent years some determinants of retail drug prices were identified. ${ }^{50-13}$ Most reported determinants are non-modifiable (eg, geographical factors, GDP and product age). However, some are modifiable. In individual studies, systems allowing for mark-ups (eg, processing costs or profit passed on to purchaser), degree of market competitiveness, the generics market proportion and degree of governmental intervention (reference pricing and education about efficacy of generics) have been found to influence drug prices in some countries. ${ }^{14-19}$ A systematic analysis of modifiable drug price determinants that are published in drug price comparison studies is, however, missing.

Therefore, in this systematic review, we aim to identify determinants of drug prices and more specifically modifiable determinants that may serve as potential targets for drug price optimisation. In addition, we give an overview of the recent literature in drug price comparisons and execute a best-evidence synthesis of all reported determinants of drug prices.

\section{METHODS}

This systematic review was guided by the Preferred Reporting Items for Systematic Reviews and Meta-Analyses (PRISMA) statement. ${ }^{20}$

\section{Patient and public involvement}

There were no patients involved in this study.

\section{Search strategy and information sources}

The databases of PubMed, EMBASE, Web of Science and the Cochrane Library were searched until 22 July 2020. We aimed to investigate which determinants influence drug prices by using comparison studies that measure at least one such determinant. All synonyms of the three topics of this study, prices, drugs/medicines and benchmark/comparison, were included in the search strategy-with the exclusion of cost-effectiveness-acknowledging the respective database formats (eTable 1 of the online supplemental materials). All peer-reviewed articles that reported drug prices (excluding price ratios) in a benchmark or comparative study were included. We did not include primary grey literature documents, such as documents of non-governmental organisations (NGOs), as our aim was to assess academic evidence of modifiable determinants, written by independent observers and published in peerreviewed journals. Both national and international studies were included, as well as pharmacy or hospital comparisons, prospective, transverse and retrospective studies. Only articles published between 2004 until and including 2020 were included for two reasons. First, our aim is to investigate current determinants of drug prices. Second, articles on this topic published before 2004 were scarce and likely less relevant, as the pharmaceutical market underwent significant changes in the last 15 years. ${ }^{21}$ Articles were excluded if they only reported (a combination of) policies, efficacy, cost-effectiveness studies or studies examining general treatment costs (such as diagnosis treatment combinations (DBCs) in the Netherlands). We executed a two-way process of reference and citation checking of the included articles.

\section{Study eligibility and outcomes}

The PICO (research format of population, intervention, control, outcome) consisted of drug or drug group (P), present determinant (I), non-present determinant $(\mathrm{C})$, drug price or price variance $(\mathrm{O})$. Therefore, all peerreviewed studies that reported a measure of association between drug prices (meaning: not relative prices or price indices) or price variance (dependent variable) and one or more determinants (independent variable(s)) were included.

\section{Selection process}

First, titles and abstracts (or if unavailable, full text) were independently screened by two researchers (JMJD and AdA). The full texts of potentially relevant articles were independently assessed for inclusion by two researchers (JMJD and AdA). Discrepancies between the researchers were resolved through discussion and consensus. If no consensus was reached, a third researcher (BvdB) was consulted.

\section{Data collection and extraction}

A standardised extraction worksheet was used to collect study characteristics, methods and outcome information from all included articles by both AdA and JMJD. The extraction worksheet was ultimately cross-checked. The following items were collected: first author name, year of publication, manuscript title, country of study, study design, selection criteria (regarding included medications, institutes), (type of) price comparison/benchmark, studied determinants of drug prices and association between determinant and drug price.

Risk of bias in individual studies and across studies Quality assessment of the included studies was done with the Quality Assessment Tool for Observational Cohort 
and Cross-Sectional Studies of the National Institute of Health (NIH) ${ }^{22}$ As the main purpose of this study is to give an overview of the field and to conduct a bestevidence synthesis, this instrument was only used to assess the quality and characteristics of the included studies and not to exclude additional studies. This specific assessment tool was used because studies were mostly cross-sectional, sometimes observational and generally heterogeneous. As this tool is only meant to guide researchers in assessing such article's strengths and weaknesses, potential consequences of the identified risk of bias were interpreted by three authors (JMJD, AdA, BvdB) and consensus was reached based mainly on potential consequences on research results, as is also recommended by the NIH. In compliance with the assessment tool methods, studies were categorised in three quality levels: good (all relevant qualifications met), fair (one or two not met) or poor (three or more not met).

Within the studies, selective reporting was assessed by carefully exploring the entire Results section and supplemental material for non-reported associations.

\section{Summary measures and evidence synthesis}

A qualitative best-evidence synthesis was performed to identify determinants of drug prices and variance in drug prices. Drug price variance reflects the potentiality of price differences of the same drug arising with comparable exposure to the analysed determinant. Unfortunately, the heterogeneity between studies meant a quantitative analysis was not feasible. Determinants measured in every study were counted. If a determinant was studied three times or more, then it was analysed and a best-evidence synthesis was conducted. If the determinant was studied once or twice, it was only shortly discussed, as the data were considered to be of insufficient robust quality for qualitative analysis. Level of evidence was based on the combination of study quality together with the total number of studies that measured the determinant. 'Strong evidence' for the price-modifying effect of a determinant was suggested if it was reported by three or more studies with an average 'fair quality' or higher and comparable associations were found. 'Moderate evidence' for the modifying effect on price or price variance of a determinant was suggested if it was reported by two 'fair quality' studies on average or higher than reported comparable associations. Pooled results with fewer studies, miscellaneous results or studies of poorer quality were considered 'poor' or 'conflicting', depending on these factors.

\section{RESULTS}

\section{Study selection}

After duplication removal and title-abstract screening, 85 full-text articles were screened for eligibility. After fulltext screening, 31 of these 85 articles were included in this systematic review. The reason for exclusion was often an irrelevant study outcome, such as drug efficacy, affordability or study design, such as reviews discussing policy.
A detailed process outline is visualised in eFigure 1 of the Supplemental Materials.

\section{Quality assessment}

Ten articles of good quality, 16 articles of fair quality and 5 articles of poor quality were identified. The criteria that caused the most differentiation in article quality were adjustment for confounding factors, sample size justification/power description/variance and effect estimates. Table 1 presents a summary of the risk of bias assessment.

\section{Study characteristics}

Of the 31 included studies, most had a cross-sectional design. Seven studies measured drug prices over a period of 1-17 years, most often with more than one follow-up. Twenty-five studies compared international prices (from here: prices) between countries, most often in highincome continents or countries such as Europe and/or the USA. Only the study by Van Harten et al reported net drug prices. ${ }^{5}$ Twenty-one studies reported retail prices (of which three government prices, two wholesale retail prices and one out-of-pocket prices) and nine studies reported ex-factory prices (table 1). Therefore, unless otherwise specified, drug prices indicate retail prices. Table 1 displays study characteristics.

\section{Determinants}

Table 1 describes all determinants measured per study and categorises the scope of the study in international versus national context. Table 2 depicts the best-evidence synthesis to which this section refers. eTable 2 of the online supplemental file 1 shows all determinants that were measured less than three times and were therefore not included in the best evidence synthesis. Below, the most common determinants of drug prices and drug price variance are described in further detail.

\section{National wealth}

Thirteen studies associated drug prices with national wealth, which was measured as a country's GDP or gross national income (GNI) per capita. Determinants in European countries were often studied because of comparable national wealth but fairly different drug pricing policies, allowing for more accurate evaluation of pricing policy efficacy. Three studies compared the most affluent European regions to other European countries, of which one included net drug prices. Seven studies compared the USA to other high-income countries. Six studies compared prices within a country, once in Austria, India, Kenya and three times in the USA. These studies addressed differences between hospitals, pharmacies, subregions and states, respectively.

While in various countries drugs became cheaper or prices remained stable over time, prices tended to increase in the USA compared with other Western countries, in some instances up to $10 \%$ per year. ${ }^{23-25}$

Medication in Northern Europe was often more expensive compared with southern Europe, although this 


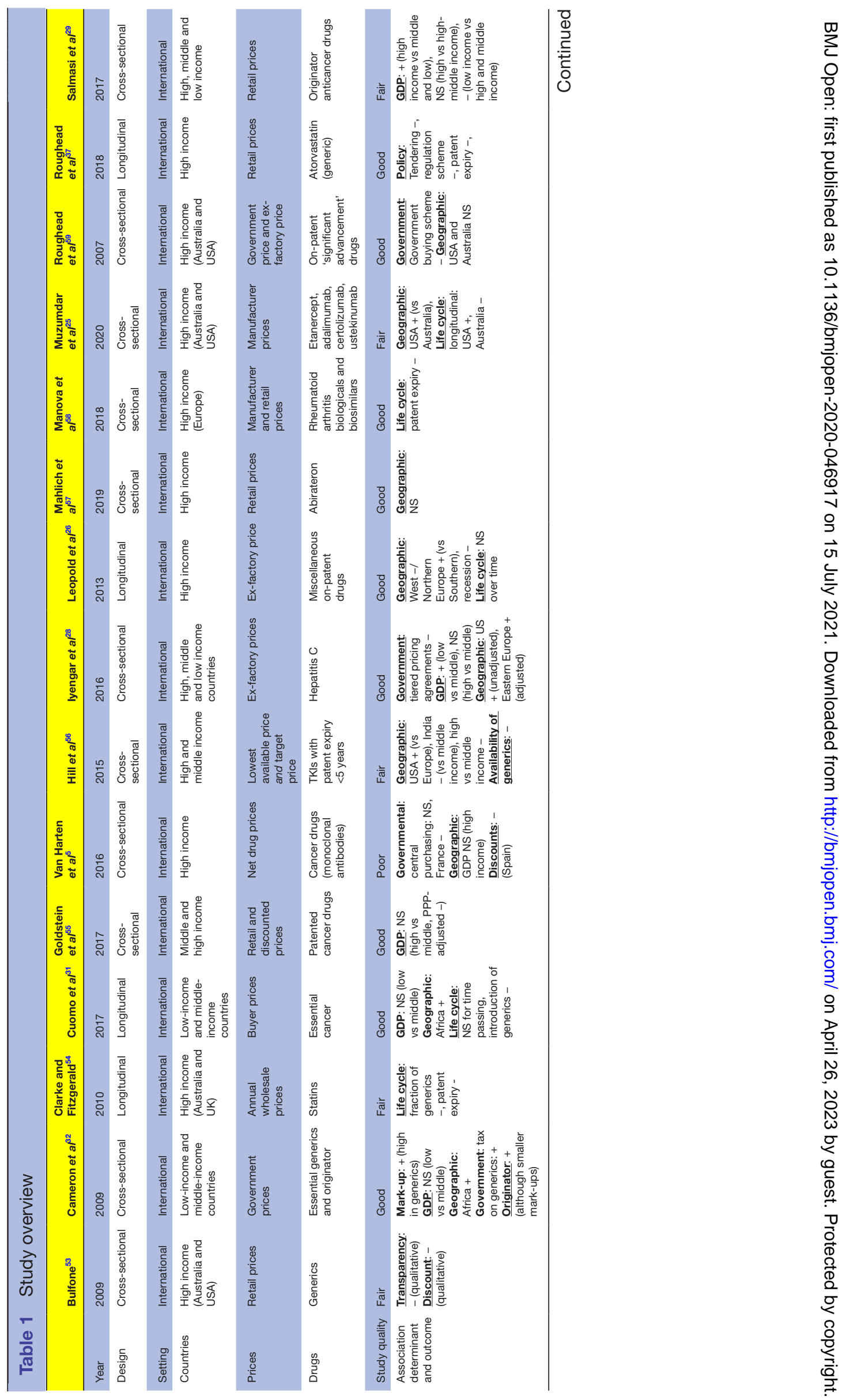




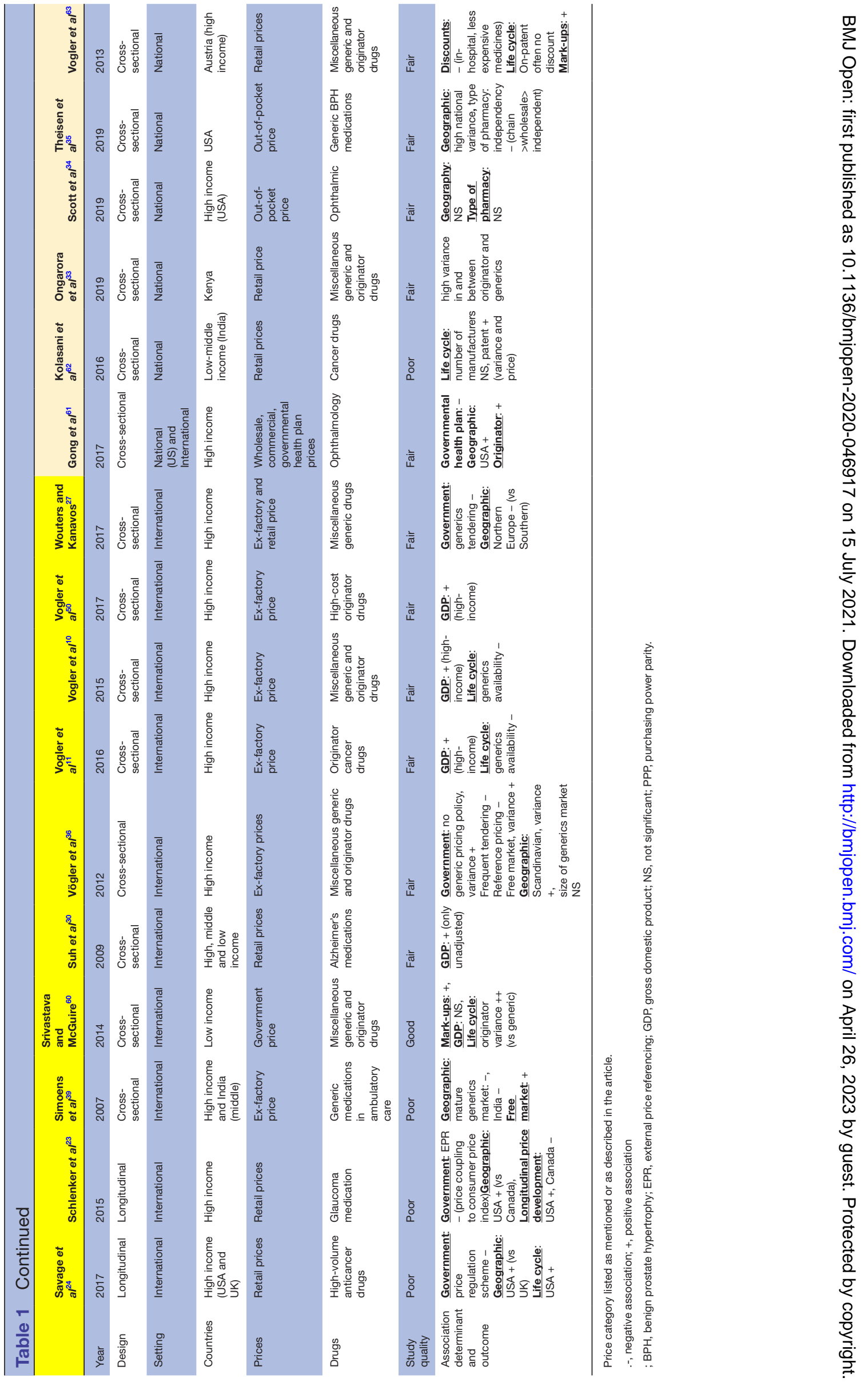




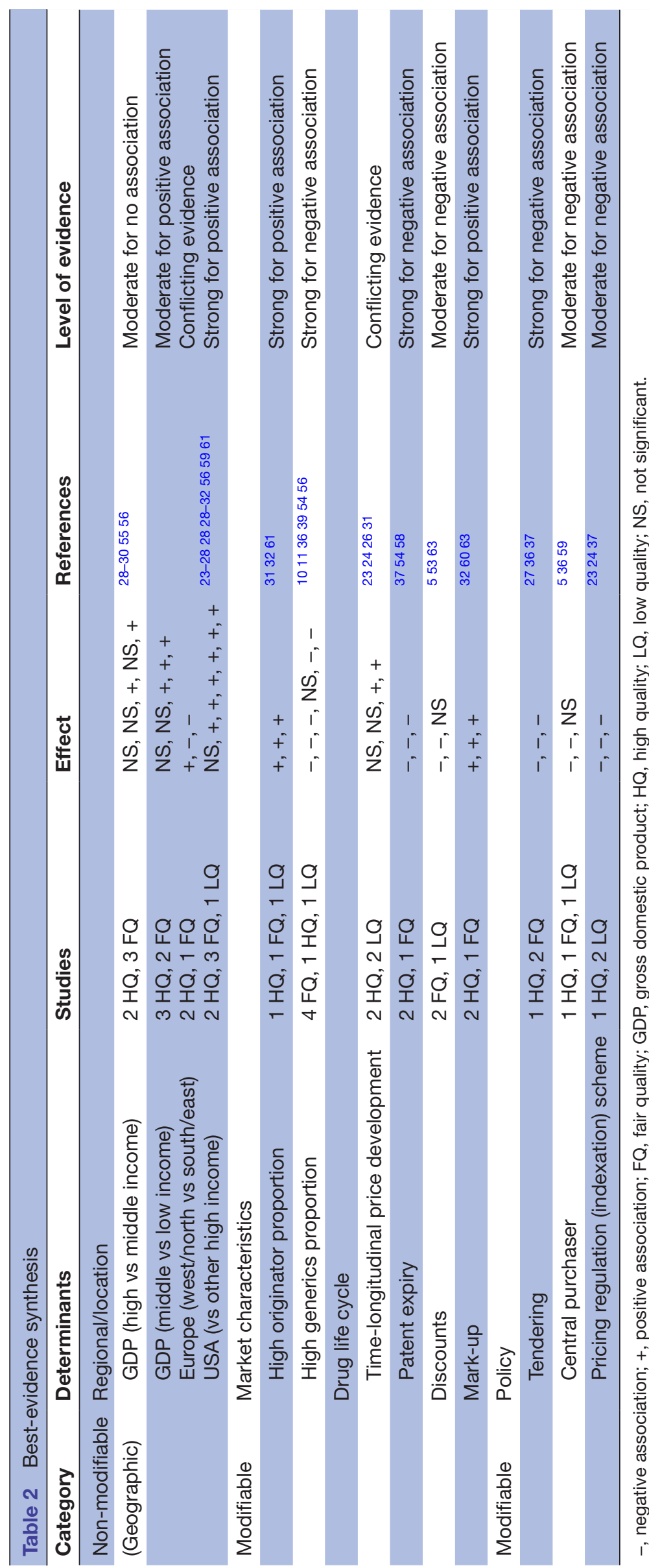

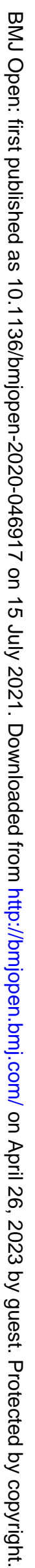


finding was inconsistent across studies and there was no consistent association between cancer drug prices and GDP in high-income European countries. ${ }^{5}$ 26-28 Conversely, after adjustment for PPP (purchasing power parity), higher GDP was associated with lower prices. ${ }^{26-28}$

Across a broad spectrum in high-income countries as well as high-income versus middle-income countries, an association between GDP and drug prices could not be established. ${ }^{511}$ Between middle-income and low-income countries, a moderately positive association between GDP and prices was found. After PPP adjustment, there was a direct relationship between GDP category and the frequency of lowest prices: across high, middle and lowincome countries, high-income countries most often had the lowest prices. ${ }^{29}{ }^{30} \mathrm{PPP}$-adjusted prices were especially high in Africa when compared with low-income and middle-income countries. ${ }^{31}{ }^{32}$ No clear association between drug prices and GDP could be established across low-income countries.

\section{Market and drugs}

Various studies assessed market influence in the form of a high proportion of generics or originators (nine studies) or patent expiry (three studies). Price-technical constructs such as discounts and mark-ups were common in five studies, of which the study by Van Harten $e t$ al included net drug prices and four described retail prices. ${ }^{5}$ Drug studies often focused on anticancer drugs (nine studies) or drugs for very specific patient groups such as hepatitis C, Alzheimer's disease or drugs for ophthalmic use. Occasionally, drugs were a random (representative) sample of widely used drugs, such as statins, analgesics and broadspectrum antibiotics, most often including generics and originator drugs.

High market proportions of originator drugs led to high prices as well as price variance in all countries. In low-middle and low-middle income countries, price variance is already significant. ${ }^{33}$ In addition, a large originator price variance arises over time in the absence of price regulation. This association is not observed for generic substitutes. Drug prices in systems allowing for mark-ups tend to be higher than systems without. Strong evidence for price reduction was found in countries with a high generics proportion in the pharmaceutical market. Patent expiry was always accompanied by price reduction. Conflicting evidence suggests that a more independent status of pharmacies (compared with a chain) is associated with lower drug prices. ${ }^{34} 35$

\section{Policies and government}

Various studies assessed the association of drug prices with specific policy measures (three studies for tendering, three for regulation scheme/indexation, three for central purchasing including one study reporting net drug prices). Of all price regulating policy measures, the strongest evidence exists for tendering. ${ }^{27} 36{ }^{37}$ Pricing regulation schemes and indexation schemes reduce price and price variance compared with unregulated market pricing. ${ }^{23} 2437$ Central purchasing by governmental agencies seems to lead to lower prices compared with semipublic or private purchasing. This effect, however, does not hold for net cancer drug prices across European countries with the exception of France. ${ }^{53637}$

\section{DISCUSSION}

This study was conducted to systematically review drug price comparison studies about the modifiable determinants of drug prices.

\section{Main findings}

We found that literature on net drug prices is very scarce and that there is very limited insight in drug pricing mechanisms, which makes it impossible for purchasers and policymakers to transparently compare drug prices. These findings are indicative of an opaque price market. As the literature only delivers anecdotal evidence for differences in net drug prices, this study is unable to comment on determinants of net drug prices to accomplish insight in pricing mechanisms which can fuel the global drug price discussion. ${ }^{5}$

Retail prices in an international and national context display a high degree of variance and not all variance can be explained by the measured determinants in this study. Despite this, we found that modifiable determinants that were associated with lower prices are as follows: a higher generics market portion, discounts, tendering policies, central (governmental) purchasing and pricing regulation schemes. Modifiable determinants that were associated with higher prices are markets with higher originators market portion and systems in which mark-ups were common. In addition, the highest and most persistently increasing prices were seen in the USA, even compared with other high-income countries. A higher GDP was associated with higher prices in middle-income versus low-income countries, but not in high-income versus middle-income countries. After PPP adjustment, highest relative prices were consistently reported in low-income countries.

\section{Turning modifiable determinants into policies}

The drug market has been subject to dramatic inflation in size as well as price over the last decades, in which expensive drugs such as anticancer drugs stand out. ${ }^{38}$ For policymakers of national governments, it is of paramount importance to know which alterations to the market and which government policies lead to lower, more affordable drug prices. Our findings about generics and originator market portions indicate that increasing the supply of generics is associated with price reductions, but this is often not the case as a stand-alone measure. For example, high-income countries with a relatively open market entry consistently experience higher initial prices for generics compared with countries with a more regulated generics market, such as Scandinavian countries with mandatory generic substitution. ${ }^{36}$ In these countries, 
prices are half those in the Netherlands and Germany, which have a relatively open market. ${ }^{39}$ Therefore, additional pricing regulation schemes might be necessary to actually achieve such a shift, and our results show various effective schemes. Direct price control by regulation on expensive drugs such as anticancer drugs likely has more influence than percentage discounts. For example, indexation to average inflation of these drugs in the UK led to an annual inflation of only a quarter percent, compared with almost $9 \%$ in the unregulated market of the USA over a period of approximately 10 years. ${ }^{24}$ In any case, pricing policy in a predominantly originator market is less likely to lead to significant price reductions than genericspromoting policy. ${ }^{40} 41$

Tendering led to lower prices and more specifically, lower generic-originator differences in various European countries. The risks of tendering include a (too) narrow focus on price and not quality. This may be of even higher importance in countries with limited quality control than in Europe and the USA, where market approval is granted after a diligent selection process by the European Medicines Agency and Food and Drug Administration. ${ }^{36}$ In addition, attention to tender frequency is important because prolonged supply exclusivity might outmarket other suppliers, leading to worsening oligopoly or even monopoly. Conversely, because of this exact reason, too high tender frequency reduces competitive pressure. ${ }^{42}$ Tiered pricing agreements have been successful in reducing drugs prices in developing countries multifold and are relatively easy to implement, although, within the scope of our study, we have not been able to collect additional proof of this. ${ }^{28}$ All in all, no intervention should be evaluated on its own; new interventions need to be weighted in the total ecosystem of interventions. Each intervention has different consequences based on the timing and sequence of implementation. Moreover, many interdependencies exist between existing measures and new interventions. ${ }^{43}$ One intervention is likely to have different outcomes in different healthcare systems. An earlier extensive review on determinants of pharmaceutical expenditure has also shed light on these dynamic properties of market interventions and governmental regulation on drug prices (as well as on investments in research and development). ${ }^{44}$

Therefore, we recommend future policy effectivity studies to include a careful assessment of (external) validity of their results; an extensive description of the healthcare system, governmental regularisation and market properties.

\section{Regional and country-specific differences}

Due to the lack of significant price differences between middle-income and high-income countries, prices did not linearly increase with GDP throughout the entire GDP spectrum. In addition, the association of GDP and drug prices reversed after PPP adjustment.

On average, a $33 \%$ increase in price was found for every $50 \%$ increase in (unadjusted) wealth per capita for a representative set of the WHO essential drugs. ${ }^{15}$ This observation is supported by the upsurge of pharmaceutical expenditure observed in steadily developing low-income and middle-income countries. ${ }^{45}$ Large price variance is noted by studies in low-income countries. This variance is largely explained by the relatively unorganised market and lack of pricing regulation. In contrast, developed countries generally have more organised price referencing systems and direct agreements with pharmaceutical companies, which means more expensive drugs can be purchased in large-scale volumes. ${ }^{46}$ Although innovative drugs in low-income countries are gradually becoming more accessible, the introduction of expensive originator alternatives of essential drugs will likely result in limited health gain but significantly increased cost. ${ }^{47}$

A large portion of the observed price differences between high-income countries originates from the USA, likely because of the unregulated free-market approach. For example, the initial price listing of expensive (cancer) drugs in the UK is negotiated by the government, in contrast to the relatively open market entry in the USA, leading to $42 \%$ lower prices in the UK. ${ }^{24}$ Currently, countries in Europe have a tendency to dovetail their healthcare system design, leading to lower and more normalised price distributions across the continent, mostly due to external price referencing. ${ }^{21}$ Indeed, consistent with our findings, this leads to further divergence from the USA. ${ }^{48}$

\section{Limitations}

The findings are to be interpreted with caution because it is likely that large heterogeneity and the lack of net pricing data added significantly to the weighting in this best-evidence analyses and the outcomes of the synthesis. Nonetheless, a significant number of studies reported no association between the measured determinant(s) and drug price(s), indicating that not only positive findings were published.

The lack of net pricing is likely partly due to the fact that we excluded primary grey literature documents from our main research corpus. Various institutions, most prominently the WHO, are increasing their efforts in assessing pharmaceutical expenditure and its determinants as shown by a recent overview of grey literature. ${ }^{49}$ Research institutes have set-up various inspiring collaborations with governmental and NGO using national databanks (such as Austria's Pharma Price Information, or PPI) or WHO data, which are rich and often available at request. ${ }^{32} 5051$ In addition, WHO now promotes and collects various drug price databases and occasionally publishes in peerreviewed journals. ${ }^{32} 52$ Ideally, these studies give rise to further collaboration and NGO-supervised observational studies in developing countries, allowing academics to assess effectiveness of interventions on net drug prices.

We recognise that the included studies only establish associations. For identifying causal associations, controlled trials are needed which are very hard to execute due to a lack of transparency and collaborative effort, as well as the difficulty of conducting an intervention ceteris paribus. 
Many studies reported large measures of uncertainty due to non-disclosure of data such as discounts, net prices paid, volumes sold, negotiations and arrangements with pharmaceutical companies. Therefore, many studies did not report an exact representation of the pharmaceutical market. Net prices may have been more economical than the retail prices reported in the literature on which this review is based, but current literature is insufficient to give further insight in net drug price determinants. This exacerbates the challenge of reducing healthcare costs, as real price comparisons are can never be made in this state of affairs.

In addition, selection bias (medication selection) is likely significant as the most complete or readily available data are used, instead of drug price data that might be less available, such as price data on confidential pricing agreements. On the contrary, the total set of included studies comprises a large variety of drugs and countries, increasing external validity of these findings.

\section{Further research}

The lack of transparency and the high prevalence of nondisclosure agreements are likely two of the major drivers for drug price differences. We call for an elimination of non-disclosure agreements to better understand underlying drug price determinants and mechanisms. In addition, we identified a gap in the representation of national studies, as only six national (within-country) analyses were identified. Therefore, we were unable to solidly identify determinants of price in the national setting.

Additional transparent, open-access research into price variance using net drug prices is needed to identify determinants of national and international price variance, which can be helpful to governments and regional institutes such as hospitals alike to improve their purchasing strategy and methods. Uniform introduction of pricing regulation and publication of net drug prices may ultimately lead to more price transparency and a more balanced playing field of countries with a significant budget constrain. Such a situation allows for fair negotiations and, ultimately, a more sustainable and transparent healthcare sector.

\section{CONCLUSION}

Peer-reviewed literature on the determinants of net drug paid prices and corresponding pricing mechanisms is very scarce. This is remarkable given the rising healthcare costs and in particular rising pharmaceutical costs, as well the growing societal discussion on mitigating healthcare expenditure. Retail drug prices display a high degree of variance, both within and between countries. This systematic review revealed empirical evidence of determinants retailing to a country's income level, its pharmaceutical market system and its policies and government. Policymakers may be particularly interested in the policy-related determinants of lower retail prices. Drug prices in lowincome countries are consistently higher after adjustment for PPP, indicating that lower-income countries still pay the highest relative retail prices. Various easily implementable governmental interventions and regulations, as well as modifiable market system-related characteristics, are consistently associated with lower retail prices and thus potential price reduction, such as increasing the generic portions of the drug market, governmental policies such as tendering, central purchasing and regulation schemes targeting annual price inflation, patent regulation and mark-ups, which might aid developing countries in closing the gap of purchasing power-adjusted prices with high-income countries in the future. Most prominently, national and international net price studies are necessary to quantify the effectiveness of these policy measures on net drug prices. We call for openness of net drug price data, as this is our key to change the healthcare cost burden.

Acknowledgements All used data are published and available online. JMJD is Jules M. Janssen Daalen, AdA is Anouk den Ambtman, BvdB is Bart van den Bemt, MVH is Mark Van Houdenhoven.

Contributors All authors contributed to the conception and design of the research. JMJD and AdA analysed the data and drafted the first manuscript version. BvdB and MVH provided in multiple sessions conceptual and detailed feedback for every version of the manuscript.

Funding The authors have not declared a specific grant for this research from any funding agency in the public, commercial or not-for-profit sectors.

Competing interests None declared.

Patient consent for publication Not required.

Ethics approval This article is a systematic review of previously published peerreviewed literature. It does not concern human research and does not use or generate data regarding characteristics or state of health of individuals.

Provenance and peer review Not commissioned; externally peer reviewed.

Data availability statement All data relevant to this study are included in the article or available as supplementary material.

Supplemental material This content has been supplied by the author(s). It has not been vetted by BMJ Publishing Group Limited (BMJ) and may not have been peer-reviewed. Any opinions or recommendations discussed are solely those of the author(s) and are not endorsed by BMJ. BMJ disclaims all liability and responsibility arising from any reliance placed on the content. Where the content includes any translated material, BMJ does not warrant the accuracy and reliability of the translations (including but not limited to local regulations, clinical guidelines, terminology, drug names and drug dosages), and is not responsible for any error and/or omissions arising from translation and adaptation or otherwise.

Open access This is an open access article distributed in accordance with the Creative Commons Attribution Non Commercial (CC BY-NC 4.0) license, which permits others to distribute, remix, adapt, build upon this work non-commercially, and license their derivative works on different terms, provided the original work is properly cited, appropriate credit is given, any changes made indicated, and the use is non-commercial. See: http://creativecommons.org/licenses/by-nc/4.0/.

\section{ORCID iDs}

Jules M Janssen Daalen http://orcid.org/0000-0001-6290-5882

Anouk den Ambtman http://orcid.org/0000-0002-3910-0290

\section{REFERENCES}

1 Keehan SP, Cuckler GA, Sisko AM, et al. National health expenditure projections, 2014-24: spending growth faster than recent trends. Health Aff 2015;34:1407-17.

2 Murthy VNR, Okunade AA, Determinants of US. Determinants of U.S. health expenditure: evidence from autoregressive distributed lag (ARDL) approach to cointegration. Econ Model 2016;59:67-73. 
3 The global use of medicine in 2019 and outlook to 2013: forecasts and areas to Watch. IQVIA Institute for Human Data Science 2019.

4 Hernandez I, San-Juan-Rodriguez A, Good CB, et al. Changes in list prices, net prices, and discounts for branded drugs in the US, 20072018. JAMA 2020;323:854-62.

5 van Harten WH, Wind A, de Paoli P, et al. Actual costs of cancer drugs in 15 European countries. Lancet Oncol 2016;17:18-20.

6 De Block M. The difficulty of comparing drug prices between countries. Lancet Oncol 2016;17:e125.

7 Dana KN, Hertig JB, Weber RJ. Drug pricing transparency: the new retail revolution. Hosp Pharm 2017;52:155-9.

8 Rintoul A, Colbert A, Garner S, et al. Medicines with one seller and many buyers: strategies to increase the power of the payer. BMJ 2020;369:m1705.

9 Shrader KR, DeSalvo RJ, Evanson RV. A comparison study of drug prices in segmented markets. J Am Pharm Assoc 1971;11:598-602.

10 Vogler S, Kilpatrick K, Babar Z-U-D. Analysis of medicine prices in New Zealand and 16 European countries. Value Health 2015;18:484-92.

11 Vogler S, Vitry A, Babar Z-U-D. Cancer drugs in 16 European countries, Australia, and New Zealand: a cross-country price comparison study. Lancet Oncol 2016;17:39-47.

12 Vogler S, Paris V, Ferrario A, et al. How can pricing and reimbursement policies improve affordable access to medicines? lessons learned from European countries. Appl Health Econ Health Policy 2017;15:307-21.

13 Ferrario A, Dedet G, Humbert T, et al. Strategies to achieve fairer prices for generic and biosimilar medicines. BMJ 2020;368:I5444

14 Kanavos PG, Vandoros S. Determinants of branded prescription medicine prices in OECD countries. Health Econ Policy Law 2011;6:337-67.

15 Hanlon M, Zhang R. Price discrimination in essential medicines: evidence from international drug price indicator guide data. Int Health 2013;5:58-63.

16 Russo G, McPake B. Medicine prices in urban Mozambique: a public health and economic study of pharmaceutical markets and price determinants in low-income settings. Health Policy Plan 2010;25:70-84

17 Yao Y, Tanaka M. Price offers of pharmaceutical procurement in China: evidence from Guangdong Province. Eur J Health Econ 2016;17:563-75

18 Dylst P, Simoens S. Does the market share of generic medicines influence the price level?: a European analysis. Pharmacoeconomics 2011;29:875-82.

19 Puig-Junoy J. Impact of European pharmaceutical price regulation on generic price competition: a review. Pharmacoeconomics 2010;28:649-63.

20 Moher D, Liberati A, Tetzlaff J, et al. Preferred reporting items for systematic reviews and meta-analyses: the PRISMA statement. BMJ 2009;339:b2535.

21 Who guideline on country pharmaceutical pricing policies World Health organization 2015.

22 Health, N.I.o. Quality assessment tool for observational cohort and cross-sectional studies. Study Quality Assessment Tools 2020.

23 Schlenker MB, Trope GE, Buys YM. Comparison of United States and Canadian glaucoma medication costs and price change from 2006 to 2013. J Ophthalmol 2015;2015:1-8.

24 Savage P, Mahmoud S, Patel Y, et al. Cancer drugs: an international comparison of Postlicensing price inflation. J Oncol Pract 2017;13:e538-42.

25 Muzumdar S, Wu R, Feng H. Temporal comparison of biologic medication prices between the United States and Australia. $J$ Dermatolog Treat 2020:1-2.

26 Leopold C, Mantel-Teeuwisse AK, Vogler S, et al. Is Europe still heading to a common price level for on-patent medicines? an exploratory study among 15 Western European countries. Health Policy 2013;112:209-16.

27 Wouters OJ, Kanavos PG. A comparison of generic drug prices in seven European countries: a methodological analysis. BMC Health Serv Res 2017;17:242

28 lyengar S, Tay-Teo K, Vogler S, et al. Prices, Costs, and Affordability of New Medicines for Hepatitis $C$ in 30 Countries: An Economic Analysis. PLoS Med 2016;13:e1002032.

29 Salmasi S, Lee KS, Ming LC, et al. Pricing appraisal of anticancer drugs in the South East Asian, Western Pacific and East Mediterranean region. BMC Cancer 2017;17:903.

30 Suh G-H, Wimo A, Gauthier S, et al. International price comparisons of Alzheimer's drugs: a way to close the affordability gap. Int Psychogeriatr 2009;21:1116-26.
31 Cuomo RE, Seidman RL, Mackey TK. Country and regional variations in purchase prices for essential cancer medications. BMC Cancer 2017; $17: 566$.

32 Cameron A, Ewen M, Ross-Degnan D, et al. Medicine prices, availability, and affordability in 36 developing and middle-income countries: a secondary analysis. Lancet 2009;373:240-9.

33 Ongarora D, Karumbi J, Minnaard W, et al. Medicine Prices, Availability, and Affordability in Private Health Facilities in LowIncome Settlements in Nairobi County, Kenya. Pharmacy 2019;7. doi:10.3390/pharmacy7020040. [Epub ahead of print: $24 \mathrm{Apr}$ 2019].

34 Scott AT, Pecen PE, Palestine AG. Ophthalmic medication price variation across the United States: anti-inflammatory medications. Ther Adv Ophthalmol 2019;11:2515841419863638:2515841419863 63.

35 Theisen KM, Park SY, Jeong K, et al. Extreme price variation for generic benign prostatic hyperplasia medications. Urology 2019;124:223-8.

36 S., V., How large are the differences between originator and generic prices? Analysis of five molecules in 16 European countries. Economics 2012.

37 Roughead EE, Kim D-S, Ong B, et al. Pricing policies for generic medicines in Australia, New Zealand, the Republic of Korea and Singapore: patent expiry and influence on atorvastatin price. WHO South East Asia J Public Health 2018;7:99-106.

38 Howard DH, Bach PB, Berndt ER, et al. Pricing in the market for anticancer drugs. J Econ Perspect 2015;29:139-62.

39 Simoens S. International comparison of generic medicine prices. Curr Med Res Opin 2007;23:2647-54

40 Sarpatwari A, DiBello J, Zakarian M, et al. Competition and price among brand-name drugs in the same class: a systematic review of the evidence. PLoS Med 2019;16:e1002872.

41 Aalto-Setälä V. The impact of generic substitution on price competition in Finland. Eur J Health Econ 2008;9:185-91.

42 Maniadakis N, Holtorf A-P, Otávio Corrêa J, et al. Shaping pharmaceutical Tenders for effectiveness and sustainability in countries with expanding healthcare coverage. Appl Health Econ Health Policy 2018;16:591-607.

43 Sood N, d.V.H. GI, Lakdawalla D. The Effect Of Regulation On Pharmaceutical Revenues: Experience. In: Nineteen Countries. Health Affairs., 2008: 27(Supplement 1), w125-37.

44 Lakdawalla DN. Economics of the Pharmaceutical Industry. J Econ Lit 2018;56:397-449

45 World Medicines Situation - Medicines Expenditures. World Health organization 2011

46 Maniadakis N, Kourlaba G, Shen J, et al. Comprehensive taxonomy and worldwide trends in pharmaceutical policies in relation to country income status. BMC Health Serv Res 2017;17:371.

47 Zaidi S, Bigdeli M, Aleem N, et al. Access to essential medicines in Pakistan: policy and health systems research concerns. PLoS One 2013;8:e63515.

48 Parliament E. D.-g.f.i.p., differences in costs of and access to pharmaceutical products in the EU 2011.

49 Borges Dos Santos MA, Dos Santos Dias LL, Santos Pinto CDB, et al. Factors influencing pharmaceutical pricing - a scoping review of academic literature in health science. J Pharm Policy Pract 2019;12:24.

50 Vogler S, Zimmermann N, Babar Z-U-D. Price comparison of high-cost originator medicines in European countries. Expert Rev Pharmacoecon Outcomes Res 2017;17:221-30.

51 Vogler S, Schneider P, Zimmermann N. Evolution of average European medicine prices: implications for the methodology of external price Referencing. Pharmacoecon Open 2019;3:303-9.

$52 \mathrm{WHO}$, World Health Organization. Medicine price information sources. Available: https://www.who.int/medicines/areas/access/ med_price_info_sources/en/ [Accessed 3rd Feb 2021].

53 Bulfone L. High prices for generics in Australia - more competition might help. Aust Health Rev 2009;33:200-14.

54 Clarke PM, Fitzgerald EM. Expiry of patent protection on statins: effects on pharmaceutical expenditure in Australia. Med J Aust 2010;192:633-6.

55 Goldstein DA, Clark J, Tu Y, et al. A global comparison of the cost of patented cancer drugs in relation to global differences in wealth. Oncotarget 2017;8:71548-55.

56 Hill A, Gotham D, Fortunak J, et al. Target prices for mass production of tyrosine kinase inhibitors for global cancer treatment. BMJ Open 2016;6:e009586.

57 Mahlich J, Sindern J, Suppliet M. Cross-National drug price comparisons with economic weights in external reference pricing in Germany. Expert Rev Pharmacoecon Outcomes Res 2019;19:37-43. 
58 Manova M, Savova A, Vasileva M, et al. Comparative price analysis of biological products for treatment of rheumatoid arthritis. Front Pharmacol 2018;9:1070

59 Roughead EE, Lopert R, Sansom LN. Prices for innovative pharmaceutical products that provide health gain: a comparison between Australia and the United States. Value Health 2007;10:514-20

60 Srivastava D, McGuire A. Analysis of prices paid by low-income countries - how price sensitive is government demand for medicines? BMC Public Health 2014;14:767.
61 Gong D, Chang JS, Barbany M, et al. Comparison of United States and international ophthalmic drug pricing. Ophthalmology 2019;126:1358-65.

62 Kolasani BP, Malathi DC, Ponnaluri RR. Variation of cost among anti-cancer drugs available in Indian market. $J$ Clin Diagn Res 2016;10:FC17-20.

63 Vogler S, Zimmermann N, Habl C, et al. The role of discounts and loss leaders in medicine procurement in Austrian hospitals - a primary survey of official and actual medicine prices. Cost Eff Resour Alloc 2013:11:15. 